\title{
Exploring Experience as a Myriad Richness: Micro-phenomenology as a Transformative Approach to Research
}

\begin{abstract}
Over the last twenty years, researches within cognitive sciences has massively grown in the field of the ways of knowing. For instance, in recent years, the paradigm of 4-E cognition suggests that cognition involves the whole body, as well as the situation of the body in the environment. This article argues that a first-person approach enriches the understanding of the ways of knowing in their complexity - particularly by seeking to re-question classical dichotomies - through the re-integration of subjective experience. In the heart of first-person epistemology, the micro-phenomenological interview - based on the explicitation interview - consists in "guided retrospective introspections", and allows to scientifically access subjective experience. This technique relies on the epoché - the suspension of judgement - a process at first investigated by philosophers that was made accessible to psychology to empirically investigate and study subjective experience. How does the epoché happen? What concrete acts make it up? More broadly, what is the relationship between the epoché and embodiment? This paper sheds lights on possible relations between researches describing concrete practices of the Husserlian epoché and Gendlin's work concerning the process of Focusing, which aims at accessing the inner felt sense of experience. The process of Focusing, is a way of paying attention to one's being-in-the-world, one's interaction as it is experienced through the individual (but not separate) body. We will especially consider the process of "clearing a space" that Gendlin describes, as well as the rupture that occurs during the "bodily felt shift" which can be compared to the conversion happening within the process of epoché. Finally, we discuss how our proposition can allow the construction of new models of knowledge processes, the challenge of such a proposal being not only epistemological, but also ethical and societal.
\end{abstract}

\section{Keywords}

Subjective experience, embodiment, micro-phenomenology, epoché, focusing.

\section{Acknowledgments and credits:}

The author thanks Dr. Regina Hess, Dr. Gabi Mihalache and Dr. Pierluigi Lattuada for the interesting discussions we had at the TRC 2019 conference in Paris. She also warmly thanks the reviewers for their valuable comments and suggestions.

\section{Author's complete name and institutional affiliation(s):}

Magali Ollagnier-Beldame

Laboratoire ICAR, Ecole Normale Supérieure de Lyon, - Site Descartes, 15 Parvis René Descartes, BP 7000, 69342 Lyon cedex 07, France

Email: magali.ollagnier-beldame@ens-lyon.fr 


\section{Exploring Experience as a Myriad Richness: Micro-phenomenology as a Transformative Approach to Research}

\section{Introduction}

In parallel with the transpersonal model, which is not only about new knowledge, but also about new contexts for knowledge and new ways of knowing (Rodrigues, 2010: 64), cognitive sciences are paying increasing attention to modes of extended knowledge. This article argues that the scientific study of subjective experience is on the one hand the condition for the development of a broader science of the ways of knowing, and on the other hand the possibility of integrating the transformative dimension of this science, a dimension that is dear to transpersonal psychology. But how can we scientifically access subjective experience, which by definition belongs to the subject's inner self? Concrete phenomenological approaches seem to be good candidates, but what is like to live the epoché on which they are based on? This paper will modestly try to delineate the outlines and the stakes of such a project honoring human experience, which seems to us both indispensable and arduous and implying a transformative dimension for researchers wishing to engage on this path.

\section{Cognitive Sciences and Subjective Experience}

Over the last twenty years, researches within cognitive sciences has massively grown in the field of the ways of knowing (Suchman, 1987, Varela Rosch \& Thompson, 1991, Hutchins, 1995, Clark, 1998). In recent years, the paradigm of 4-E cognition (for embodied, embedded, enactive and extended cognition) suggests that cognition involves the whole body, as well as the situation of the body in the environment (Newen de Bruin \& Gallagher, 2018). The principle of a cognition rooted in an embodied subject, situated into a particular setting is the foundation of the theory of enaction (Varela Rosch \& Thompson op. cit.). This theory considers cognition as an "embodied action", i.e. as a phenomenon rooted in the constant interactions between the subject and her environment and by which these two realities co-occur. But although the goal of researches within the paradigm of 4-E cognition is to understand the Human "in situation", they rely mostly on many dualisms (subject vs. object -, action vs. cognition, inner vs. outer, body vs. psyche, innate vs. acquired), often considered as contradictions and considered by sciences as antagonisms or aporias. According to the philosopher of complexity Morin (1990), the non-integration of these contradictions leads to a "blind intelligence", a simplifying scientific thought that disfigures and mutilates reality through disjunctions (separating what is linked), reductions (unifying what is diverse) and abstractions (isolating objects from their environment). According to him, on the contrary, it is necessary to move on to a complex generalized thought - in the etymological sense of complexus: "what is woven together" - integrating these contradictions and linking what seems to be opposed. In the same vein, Varela, Rosch and Thompson (op.cit.) and Depraz, Varela and Vermersch (2003) argue for taking into account these dualities, without seeking to go beyond them by synthesizing them, but recognizing them the possibility to co-occur. For them, subjective experience, as a research material, is the possible place where these dualities can be integrated because, owing to its "intermediate" nature, experience questions the relevance of these dualities. In this direction, we defend the need for a new paradigm for the study of the ways of knowing rehabilitating and reintegrating lived experience at the core of the process (Petitmengin Bitbol \& Ollagnier-Beldame, 2015). Thus, with Braud and Anderson (1998), we argue that the full spectrum of human experience and its scientific description should be at the heart of human and social sciences, since it is a way to study and honor subjectivity: Honoring human experience is an ordinary human exploration practiced here in the focused context of research. It particularly requires approaching each research topic with a beginner's mind, an attitude that feels wonder, enjoyment, surprise, playfulness, awe, and deep appreciation (ibid.: xxvii).

To commit this path, the irreducible complexity of knowledge processes needs an open interrogation method, considering their phenomenal manifestations, i.e. the way they are from a "first-person" subjective - perspective, relying on a first-person epistemology that considers subjectivity as it is 
experienced by the subject herself (Varela \& Shear, 1999, Depraz, 2014) ${ }^{1}$. With Bitbol and Petitmengin (2011: 36), we contend that gathering authentic descriptions of lived experiences is the first and necessary step to ground our research in the things themselves and access the invariant structure of experience. According to what the phenomenological approach aims at, the objective is then to identify structures of experience beyond their content, as Fuchs (2002) reminds us. Thus, as we wrote in (Petitmengin Bitbol \& Ollagnier-Beldame, 2015), once a corpus of singular descriptions of experiences has been collected, a whole work of reorganization, analysis and formalization is necessary in order 1. To identify the possible structure of the described experiences, i.e. a network of relationships between descriptive categories, independently from the experiential content, and, 2. To detect any generic structures, progressively extracted from the initial descriptions thanks to a succession of operations of abstraction (Petitmengin Remillieux \& Valenzuela-Moguillansky, 2018, Ollagnier-Beldame \& Coupé, 2019, Valenzuela-Moguillansky \& Vásquez-Rosati, 2019).

\section{Micro-phenomenology as a Way to Explore the Richness of Experience}

At the heart of first-person epistemology, micro-phenomenology (Petitmengin, 2006, Bitbol \& Petitmengin, 2016) is based on enaction and neurophenomenology (Varela, 1996). Interested in "what it is like to be" (Nagel, 1974), the micro-phenomenology seeks precisely to understand the complexity of the human experience with an emic approach, i.e. using data from the "discourse" of subjects as opposed to an etic approach, i.e. using observational data (Olivier de Sardan, 1998).

This discourse is not a narration but relies on what Vermersch (1994) calls the "embodied posture of Speech" (EPS), or "evocation", which is the verbalization of experience in close contact with it. The "level of experiencing" (Hendricks, 2001) is the degree of connection between what a person is saying and her experience when she says it. It is a quantifiable first-person process: there are low, medium and high levels of experiencing. The micro-phenomenological interview aims at a high level of experiencing in order to facilitate the experiential description. The experiencing scale (Hendricks, 2009), which measures this process, is the third-person evaluation of a first-person process, based on specific linguistic and somatic indicators.

The micro-phenomenological interview relies on the explicitation interview, developed by Vermersch (op.cit., 2012) and Petitmengin (2006) $)^{2}$. It consists in "guided retrospective introspections", aiming at accompanying an interviewee in recalling a past situation. It does not, however, guide the subject on the content she verbalizes, which comes to her consciousness through a movement of letting go. This is possible thanks to a specific posture from the interviewer guiding the interviewee's attention with open and non-inductive questions but never inducing the content of what the latter says. During this movement, the interviewee is accompanied by the interviewer to suspend her judgment - the

\footnotetext{
1 They are defined this way as opposed to the third-person point of view that does not allow to study the experience as it focuses on behaviors and examines them according to predefined categories. This point of view implies a third-person epistemology in which subjectivity and lived experience are generally viewed as epiphenomena or as being beyond the reach of science (Vermersch, 2000).

It has been supplemented by a method of data analysis and validation (Petitmengin, Bitbol \& OllagnierBeldame, 2015 ; Petitmengin, Remillieux, Valenzuela-Moguillansky, 2018).
} 
Husserlian epoché (Depraz Varela \& Vermersch, 2003) ${ }^{3}$-, which allows her to access her past lived experience. The main characteristics of the explicitation interview are:

1. The EPS within the interviewee, allowing her to initiate and to maintain an intimate contact with the evoked past situation;

2. The concept of "satellites of action", to help the interviewer be aware of the area of verbalization to which the interviewee is referring to and to drive the interviewee's attention according to these areas;

3. The contact with a singular past situation (unique in time and space) in order to collect specific descriptions rather than generalizations (such as know-how or habits);

4. The holistic description of the lived experience in the entanglement of its cognitive and bodily dimensions, beyond the division;

5. The precise use of perlocutionary effects (Austin, 1962);

6. The consideration of the temporality of the experience, carefully explored by the interviewer who is guiding the fragmentation of the interviewee experience into a series of very detailed phenomena through specific questions.

Like the explicitation interview, the micro-phenomenological interview aims to describe the experience in an intuitive mode (as opposed to signitive, purely conceptual), i.e. based on a presentification of the past moment.

It is important to bear in mind that first-person epistemology is not an epistemology of immediacy since experience is not directly accessible to the subject (Braud \& Anderson, 1998; Castro, 2009) and that the first-person perspective should not be confused with immediate donation, i.e., for the subject, a sudden, clear and distinct illumination (Vermersch, 2000). Indeed, being epistemically related to facts about oneself is not a sufficient condition for first-person perspective taking: According to Pauen (2012: 37-38), you can also have an objective, third-person view on your headache. [...] What is needed is a difference not in terms of the epistemic object but, rather, in terms of epistemic access even if it may turn out to be necessary to refer to specific epistemic objects in order to clarify what the specific kind of access is. The decisive point seems to be that there are certain features of oneself that do require a specific kind of epistemic access. It is precisely an epistemic access to experience that is both unusual and privileged that the micro-phenomenological interview offers.

\section{Being More Freshly Present: About the Importance of Epoché}

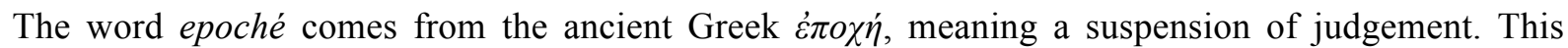
process, at first investigated by philosophers such as Husserl (1989), was made accessible to psychology to empirically investigate and study subjective experience (Giorgi, 2009, 2014; Depraz Varela \& Vermersch, 2003). Epoché means a bracketing of all preconceived ideas and prejudices in order to allow a full concentration on the perception of the phenomenon (Moustakas, 1994). The expression "active neutrality" (Bois, 2007) to designate this act of suspension indicates the double character of this movement: it is an active letting come. However, the concrete acts of the epoché and the associated subjective experience are poorly documented. Indeed, how does the epoché happen? How does it feel to perform this process? What are its inner gestures (Koch, Fuchs, Summa \& Müller,

According to (Depraz Varela \& Vermersch, 2003: 25)

One accomplishes the epoché in three principal phases:

A0: Suspending your "realist" prejudice that what appears to you is truly the state of the world;

this is the only way you can change the way you pay attention to your own lived experience; in

other words, you must break with the "natural attitude."

A1: Redirecting your attention from the "exterior" to the "interior."

A2: Letting-go or accepting your experience. 
2012)? What relationship to oneself, to others and to the world (e.g. the quality of presence) may unroll during this process? Does it go beyond the suspension of judgment? More broadly, what is the relationship between the epoché and embodiment? We propose a line of thought on these questions in shedding light on possible connections between researches describing concrete practices of the Husserlian epoché (Depraz, Varela \& Vermersch, 2003) and Gendlin's work (1962/1997, 1978) especially the process of "clearing a space" that he describes (1978), as well as the rupture that occurs during the "bodily felt shift" which can be compared to the conversion happening within the process of epoché.

\section{Focusing and Clearing a Space}

Eugene Gendlin (1981) developed a six steps mind/body process for accessing the inner felt sense ${ }^{4}$ of experience, out of research Carl Rogers and he conducted on what led to successful psychotherapy. This process is called Focusing, and it is a way of paying attention to one's being-in-the-world, one's interaction as it is experienced through the individual (but not separate) body. The first step of Focusing, "Clearing a Space" (CAS), can be used as an entrance into the complete Focusing process, or as a whole step unto itself. CAS involves "putting down" issues carried as bodily tensions, until the body can be experienced significantly free of tensions for a while. People are invited to install comfortably and to relax their body. Then they are guided to take a mindful inventory of the issues and feelings that are in the way of experiencing a sense of decluttering; placing these "things" in a distant place outside of their body, until they feel a sense of reaching an endpoint. As these things are set aside, the weight is lifted and a new freeing energy comes into the body, CAS putting people in touch with a natural life affirming energy that is always available yet is often blocked or buried by issues. The idea is not to solve the issues but to live the bodily experience of "setting it down" for a few moments and being able to feel what the body feels like when it is temporarily free of carrying any issues. The person can stop after CAS to carry on relaxation, or may pick one of the issues put at a distance and continue with the whole Focusing process. Indeed, originally, CAS was included in the Focusing instructions as a means of reducing distractions, in order to "Focus" on something-much like clearing a desk before tackling a project (Rappaport, 2010). However, over time, Gendlin and others noticed that nothing but the process of CAS had significant beneficial results, such as centering, relaxation, and access to spiritual dimensions (Gendlin, 1962/1997; Grindler, 1991; Klagsbrun,et al., 2005).

\section{Discussion}

The epoché is a condition for a phenomenological access to subjective experience. It allows an opening, an active availability allowing a receptive letting come. When it arises, it leads to a balance within the person between activity and passivity; in order to access the subjective experience with a certain freshness, which recalls the "beginner's mind" of Braud and Anderson (1998). This free availability seems to be related to the process of clearing a space described by Gendlin. Indeed, a person whose body is momentarily freed from tensions, accesses an opening to herself and to the world allowing fresh meaning and knowledge to arise, which can lead to a transformation, bringing her "closer to herself".

In this article, we exposed the privileged role of the body and bodily sensations within intuitive knowledge. Along the lines of this proposition, a new relationship to the body, as a source of knowledge, can be sketched. Berger and Vermersch (2006) speak of "bodily epoché" to describe some practices that involve a break with a certain habitual relationship to the body, to let come a listening, an observation and a feeling that lead to the constitution of a specific universe, the latter only happening in these actual conditions of reduction (ibid.: 46, our translation), such an epoche allowing "a renewed relationship to the body, more present, different from a mechanical relationship" (ibid.). Berger and Vermersch consider the epoché as a gesture. By drawing a parallel between an attentional gesture (the Husserlian epoché) and a corporal gesture (bodily epoché), they aggregate these acts as being able to help refining the practice of reduction (in the phenomenological sense), i.e. suspending

4

Gendlin's bodily felt sense is a holistic unity that cannot be divided into the traditional divisions of mind and body. 
the natural relationship to phenomena in order to let hidden aspects of them appear. The research about the ways of knowing would surely benefit from this new status of the human experience and bodily sensations.

A first-person approach as described above aims to enrich the understanding of the ways of knowing in their complexity - particularly by seeking to re-question classical dichotomies - through the reintegration of subjective experience. Combined with a third-person approach, it can allow the construction of new models of knowledge processes, more operative than models made solely from third-person data, which can not grasp the phenomenological dimension in which the Living "dwells" and "decides" within the concret and embodied complexity. Finally, we claim a holistic approach to knowledge processes fully considering human subjectivity through experience, beyond the normativity of subjectivity. To achieve this goal, it seems essential to broaden our conception of the subject and the world and to accept to be obedient to the authority of the Living in its dynamic and processual dimensions, and in its contradictions. The challenge of such a proposal is not only epistemological, but also ethical and societal. Indeed, what gives the person the feeling of being the person she is, if not her experience? Is not experience "the only tangible reality of the person, at the forefront of the Living being alive" (Lamboy, 2003)? Leaving aside lived experience, does not that mean depriving oneself of a considerable source of knowledge ? Re-integrating the Living into the study of knowledge processes would help develop an ecosystemic vision of the person as a complex unit that shapes in the relationship between her organism and the environment. This vision also fosters an understanding of the relationship between humans and Nature, allowing for both non-dissociation and differentiation, thus bringing together the seemingly contradictory notions of belonging and autonomy.

\section{Funding information}

The author is grateful to the LABEX ASLAN (ANR-10-LABX-0081) of the Universite de Lyon for its financial support within the program Investissements d'Avenir (ANR-11-IDEX-0007) of the French government, operated by the National Research Agency (ANR). She also thanks, for their financial support, the Institut Rhônalpin des Systèmes Complexes (IXXI), the Research Fund of the Ecole Normale Supérieure of Lyon and the Direction of Research and Doctoral Schools of the Université Lyon 2.

\section{References}

Austin, J. L. (1962). How to do things with words. Cambridge, Mass.: Harvard university press.

Berger, E. \& Vermersch, P. (2006). Réduction phénoménologique et épochè corporelle : Psychophénoménologie de la pratique du 'point d'appui'. Expliciter 67, 45-50.

Bitbol, M. \& Petitmengin, C. (2011). On pure reflection - A reply to Zahavi, Journal of Consciousness Studies 18-2, 24-37.

Bitbol, M. \& Petitmengin, C. (2016). On the possibility and reality of introspection. Mind and Matter 14-1, 51-75

Bois, D. (2007). Le corps sensible et la transformation des représentations de l'adulte. Thèse de doctorat de 3è cycle en Sciences de l'éducation, Dépt de Didactique et Organisation des Institutions Éducatives. Université de Séville (Espagne)

Braud, W. \& Anderson, R. (1998). Transpersonal research methods for the social sciences: Honoring human experience. Thousand Oaks, CA: Sage.

Castro, M. (2009). Talking of transcendence: A discursive exploration into how people make sense of their extraordinary experiences. Unpublished Thesis. University of York.

\footnotetext{
5
}

Indeed, "nothing is as debilitating as a confused and distant functioning of experiencing" (Gendlin, 1962:1516). 
Clark, A. (1997). Being There: Putting Brain, Body, and World Together Again. Cambridge: Massachusetts Institute of Technology Press. https://doi.org/10.7551/mitpress/1552.001.0001

Depraz, N. (ed.). 2014. Première, deuxième, troisième personne. Zeta Books.

Depraz, N., Varela, F. \& Vermersch, P. (2003). On becoming aware. An experiential pragmatics. Boston/Amsterdam, Benjamins Press. https://doi.org/10.1075/aicr.43

Fuchs, T. (2002). The challenge of neuroscience: Psychiatry and phenomenology today. Psychopathology 35, 319-326. https://doi.org/10.1159/000068593

Gendlin, E. (1962/1997). Experiencing and the creation of meaning. Northwestern University Press. https://doi.org/10.1037/t29376-000

Gendlin, E. (1978). Focusing (first edition). New York: Everest House.

Giorgi, A. (2009). The descriptive phenomenological method in psychology: A modified Husserlian approach. Pittsburgh, PA: Duquesne University Press.

Giorgi, A. (2014). Phenomenological Philosophy as the Basis for a Human Scientific Psychology. The Humanistic Psychologist, 42: 233-248. https://doi.org/10.1080/08873267.2014.933052

Grindler, D. (1991). Clearing a space and cancer: The use of focusing as a psychological tool for adaptive recovery. Unpublished doctorial dissertation, Illinois School of Professional Psychology, Chicago, IL.

Husserl, E. (1989). La Crise des sciences européennes et la phénoménologie transcendantale. Gallimard, La Haye.

Hutchins, E. (1995). Cognition in the wild. Cambridge: Massachusetts Institute of Technology Press.

Klagsbrun, J., Rappaport, L., Speiser, V. et al (2005). Focusing and Expressive Arts Therapy as a Complementary Treatment for Women with Breast Cancer. Journal of Creativity in Mental Health, 1-1, 101-137. https://doi.org/10.1300/J456v01n01 08

Koch, S., Fuchs, T., Summa, M. \& Müller, C. (Eds.). (2012). Body Memory, Metaphor and Movement. Amsterdam, The Netherlands: John Benjamins. https://doi.org/10.1075/aicr.84

Lamboy, B. (2003). Devenir qui je suis. Paris Desclée De Brouwer.

Morin, E. (1990). Introduction à la pensée complexe, Le Seuil.

Moustakas, C. (1994). Phenomenological Research Methods. Thousand Oaks: Sage

Nagel, T. (1974). What is it like to be a bat? The Philosophical Review, 4, 435-450. https://doi.org/10.2307/2183914

Newen, A., de Bruin, L., Gallagher, S. (eds) (2018). The Oxford handbook of 4E cognition, Oxford University Press, Oxford. https://doi.org/10.1093/oxfordhb/9780198735410.001.0001

Olivier de Sardan, J.-P. (1998). Émique, L'Homme, numéro thématique Alliance, rites et mythes, 38-147, 151-166. https://doi.org/10.3406/hom.1998.370510

Pauen, M. (2012). The Second-Person Perspective. Inquiry, 55-1, 33-49. https://doi.org/10.1080/0020174X.2012.643623 
Petitmengin, C. (2006). Describing one's Subjective Experience in the Second Person. An Interview Method for the Science of Consciousness, Phenomenology and the Cognitive Sciences, 5, 229-269. https://doi.org/10.1007/s11097-006-9022-2

Petitmengin, C., Bitbol, M., Ollagnier-Beldame, M. (2015). Vers une science de l'expérience vécue. Intellectica 64, 53-76. https://doi.org/10.3406/intel.2015.1012

Petitmengin, C., Remillieux, A. \& Valenzuela-Moguillansky, C. (2018). Discovering the structures of lived experience. Towards a micro-phenomenological analysis method. Phenomenology and the Cognitive Sciences. https://doi.org/10.1007/s11097-018-9597-4

Rappaport, L. (2010). Focusing art-therapy and trauma. Journal of Person-centered and Experiential Psychotherapies, 9-2, 128-143. https://doi.org/10.1080/14779757.2010.9688513

Rodrigues, V.-J. (2010). Transpersonal approach in 15 questions. Integral Transpersonal Journal. $0-0,53-71$.

Suchman, L. (1987). Plans and situated actions. The problem of human/machine communication. Cambridge: Cambridge University Press.

Valenzuela-Moguillansky, C. \& Vásquez-Rosati, A. (2019). An analysis procedure for the microphenomenological interview. Constructivist Foundations 14-2, 123-145.

Varela, F., Rosch, E. \& Thompson, E. (1991). The Embodied Mind. Cognitive Science and Human Experience. MIT Press. https://doi.org/10.7551/mitpress/6730.001.0001

Varela, F. \& Shear, J. (1999). First-Person Methodologies: What, Why, How? Journal Consciousness Studies. 6 2-3, 1-14.

Vermersch, P. (2000). Conscience directe et conscience réfléchie. Intellectica 31, 269-311. https://doi.org/10.3406/intel.2000.1609 